\title{
PENGARUH METODE LATIHAN PLYOMETRIC TERHADAP KEMAMPUAN JUMPING SMASH BOLA VOLI SISWA EKSTRAKURIKULER SMPN 1 BERMANI ILIR KABUPATEN KEPAHIANG
}

\author{
EDWAN \\ Universitas Bengkulu \\ edwan2796@gmail.com \\ Ari Sutisyana \\ Universitas Bengkulu \\ Bogy Restu Ilahi \\ Universitas Bengkulu
}

\begin{abstract}
Abstrak
Penelitian ini bertujuan untuk mengungkapkan pengaruh latihan plyometric terhadap kemampuan jumping smash siswa ekstrakurikuler SMPN 1 Bermani llir Kabupaten Kepahiang. Adapun rumusan masalah dalam penelitian ini adalah Apakah ada pengaruh metode latihan plyometric terhadap kemampuan jumping smash bola voli Siswa Ekstrakurikuler SMPN 1 Bermani llir Kabupaten Kepahiang Penelitian ini dilakukan di SMP N 1 Bermani llir Kabupaten Kepahiang pada tahun 2017. Metode penelitian yang digunakan Quasi Eksperimen Design yaitu dengan menggunakan rancangan One-Group Pretest-posttest design, penelitian ini secara objektif atau apa adanya dengan sampel 20 orang atlet dengan cara menjadikan semua populasi menjadi sampel (total sampling). Berdasarkan hasil pengujian statistik dengan hasil thitung $<\mathrm{t}$ tabel $(4,14<1,740)$ artinya terbukti bahwa ada pengaruh yang signifikan latihan plyometric terhadap kemampuan jumping smash bola voli, sedangkan perentase latihan plyometric berpengaruh terhadap jumping smash yaitu sebesar $(17,13 \%)$.
\end{abstract}

Kata kunci: Plyometric, Jumping Smash dan permainan bola voli

\begin{abstract}
This study aims to reveal the effect of plyometric exercise on the ability of jumping smash extracurricular students SMPN 1 Bermani llir Kepahiang Regency. The formulation of the problem in this research is Is there any influence of plyometric training method on the ability of jumping smash volleyball Student Extracurricular SMPN 1 Bermani llir Kepahiang Regency This research was conducted in SMP N 1 Bermani llir Kepahiang Regency in 2017. The research method used Quasi Experimental Design is Using the One-groub Pretest-posttest design, this study is objective or as is the case with a sample of 20 athletes by making all populations into samples. Based on the results of statistical tests with t count $<t$ table $(-4.14$ $<1.740$ ) means that there is a significant effect of plyometric exercise on the ability of jumping smash volleyball, while the percentage of plyometric exercise affect the jumping smash that is equal to $(17.13 \%)$.
\end{abstract}




\section{Keywords: Plyometric, Jumping Smash and Volleyball Game}

\section{PENDAHULUAN}

Pelaksanaan pendidikan jasmani dan olahraga merupakan sebuah investasi jangka panjang dalam upaya pembinaan mutu sumber daya manusia Indonesia. Hasil yang diharapkan akan dicapai dalam jangka yang cukup lama. Karena itu upaya pembinaan bagi peserta didik melalui pendidikan jasmani dan olahraga perlu ditingkatkan dengan kesabaran dan keikhlasan. Seiring dengan upaya penyempurnaan permainan agar lebih menarik, maka unsur dalam permainan bola voli mangalami perubahan, baik dalam sejarah, perkembangan permainan bola voli menyangkut empat hal pokok, yaitu teknik, perturan permainan, sarana dan perlengkapan permainan.

Perkembangan teknik diarahkan pada peningkatan keterampilan gerak, dirancang agar bola yang dimainkan dapat dilewati melalui jaring ke lapangan lawan sehingga lawan tidak mampu mengembalikan bola atau mengalami kesulitan untuk mengembalikan bola dengan baik, tanpa mengabaikan peraturan permainan. Menurut, Soleh (2014:8) teknik dasar bola voli ada empat macam yaitu: servis, passing, blocking, dan smash. Teknik smash sangat diperlukan didalam permainan bola voli, Menurut Dieter Beutelstahl (2007:24), kalau pemain hendakmemenangkan pertandingan bola voli, maka mau tidak mau mereka harus menguasai bola voli merupakan salah satu cabang olahraga yang memasyarakat di Indonesia. karena permainan ini dapat dilakukan orang dewasa maupun anak-anak. Pembinaan prestasi dalam cabang olahraga bola voli dapat dicapai melalui latihan yang terprogram, teratur dengan melibatkan berbagai disiplin ilmu pengetahuan dan teknologi. Setiap cabang olahraga membutuhkan latihan fisik untuk mencapai prestasi yang maksimal. Latihan fisik pada setiap cabang olahraga merupakan dasar utama yang harus dilakukan selain meningkatkan latihan teknik dan taktik.

Olahraga bola voli kemampuan otot tungkai sangat di perlukan untuk jumping smash. Teknik jumping smash sangat di pengaruhi oleh kualitas otot tungkai. Untuk dapat melakukan teknik jumping smash dengan baik diperlukan unsur kekuatan dan kecepatan dari sekelompok otot yang mendukung gerakan tersebut. Dari sekelompok otot yang paling dominan mendukung terhadap jumping smash adalah otot tungkai. Salah satu jenis metode latihan untuk meningkatkan explosive power adalah dengan metode latihan plyometric.

Plyometric merupakan salah satu metode latihan yang sering digunakanoleh para pelatih untuk meningkatkan explosive power. Pelatih atletik asal rusia padatahun 1960 Yuri Veroshanki yang dikutip dari (lubis,2013:74), Menggunakan metode latihan plyometric kepada atlet lompatnya dan mengalami kesuksesan yang luar biasa dipertandingan. Dalam plyometric, beban yang digunakan sering dengan menggunakan berat badan sendiri atau alat-alat lain yang dapat memberikan rangsangan pada otot. Di kabupaten kepahiang khususnya di Ekstrakurikuler Bola Voli SMPN 1 Bermani Ilir, pembinaan sudah dilakukan dengan baik dan sudah banyak prestasi yang didapatkan dari atlit-atlit Ekstrakurikuler Bola Voli SMPN 1 Bermanillir Kabupaten Kepahiang, dalam perkembanganya Ekstrakurikuler Bola Voli SMPN 1 Bermani llir Kabupaten Kepahiang ini guru mengalami kesulitan latihan untuk peningkatan jumping smash atlit-atlit nya, jumping yang tinggi sangat diperlukan didalam permainan bola voli jumping yang 
tinggi tidak hanya digunakan untuk smash tetapi digunakan juga pada saat blok dan servis. Berdasarkan hasil observasi dan wawancara dengan pembina Ekstrakurikuler Bola Voli di SMPN 1 Bermani llir Kabupaten Kepahiang, diketahui bahwa kemampuan melakukan jumping Smash sangat rendah hal ini merupakan salah satu kendala dalam peningkatan prestasi Ekstrakurikuler Bola Voli di SMPN 1 Bermani llir Kabupaten Kepahiang, Berkenaan dengan uraian di atas, penulis mencoba melakukan penelitian dengan judul "Pengaruh Metode Latihan Plyometric terhadap Kemampuan Jumping Smash Bola Voli Siswa Ekstrakurikuler SMPN 1 Bermani llir Kabupaten Kepahiang".

\section{METODE}

Berdasarkan tujuan dalam penelitian ini yaitu untuk mengetahui Pengaruh Metode Latihan Plyometric Terhadap Peningkatan Jumping Smash Bola Voli siswa Ekstrakurikuler SMPN 1 Bermani llir. Menurut subana (2005:95) Penelitian eksperimen merupakan penelitian yang dimaksudkan untuk menguji hipotesis berbentuk hubungan sebab akibat melalui pemanipulasian variaabel independen. Adapun bentuk penelitian yang digunakan dalam penelitian ini adalah penelitian kuantitatif dengan menggunakan metode pre eksperimen. Menurut Sugiyono (2006:82) "Bentuk pre-experimental designs ada beberapa macam yaitu: One-shot Case Study, One-Group Pretest-Posttest Design, dan Intact-Group Comparison". Dari ketiga bentuk yang dipaparkan tersebut maka peneliti memilih model One-GroupPretestPosttes Design.

Populasi adalah keseluruhan subjek suatu penelitian Arikunto (2006:55), sedangkan populasi adalah keseluruhan darikara kteristik atau unit hasil pengukuran yang menjadi objek penelitian. Jadi populasi dalam penelitian ini adalah siswa Ekstrakurikuler SMPN 1 Bermani Ilir. berjumlah 20 orang. Sampel adalah sebagian atau wakil populasi yang diteliti Arikunto, (2006:117). Jumlah sampel pada penelitian ini sebanyak 20 orang maka penulis mengambil semua populasi tersebut atau totalsampling. Data yang digunakan dalam penelitian ini adalah data kekuatan otot tungkai dan data Jumping Smash. Data kekuatan otot tungkai dan jumping smash digunakan untuk menentukan data pretest. Seluruh data yang diperlukan dalam penelitian ini seperti yang tersebutdi atas, diperoleh melalui tes dan pengukuran terhadap kekuatan otot tungkai dengan menggunakan vertical power jump test untuk mengumpulkan data power otot tungkai.dan Tes Jumping Smash.

\section{HASIL DAN PEMBAHASAN Hasil}

Berdasarkan hasil penjelasan serta uraian yang telah dikumpulkan sebelumnya, maka pada bab ini akan mencari hasil penelitian analisis data dan pembahasan yang diperoleh dengan menggunakan statistik. Dari satu kelompok yang dijadikan kelompok eksperimen latihan plyometric. Semua data yaitu 20 sampel memenuhi persyaratan untuk diolah dalam penelitian ini. Data lengkap mengenai hasil tes awal dan tes akhir kemampuan jumping smash menggunakan latihan plyometric dapat dilihat pada lampiran. Deskripsi data dari masing-masing variabel dikemukakan di bawah ini.

Dari hasil penelitian yang dilakukan di dapatkan hasil dari tes awal dan akhir beseta dengan uji prasyarat yaitu normalitas dan homogenitas.

Tes awal

Hasil penelitian menunjukkan bahwa distribusi skor tes awal kemampuan jumping 
smash yang diukur dengan menggunakan testsebanyak 5 kali smashtiap pelaksanaan. Berdasarkan hasil tes pre-test diperoleh rata-rata hitung $=3,35$ standar deviasi $=$ 1,54 nilai minimum $=1$, dan maksimum $=6$. Tes akhir

Hasil penelitian menunjukkan bahwa distribusi skor tes akhir kemampuan jumping smash yang diukur dengan menggunakan test sebanyak 5 kali tiap pelaksanaan. Berdasarkan hasil tes post-test diperoleh rata-rata hitung $=9,4$, standar diviasi $=$ 2,93 , nilai minimum $=4$, nilai maksimum $=$ 15.

Setelah uji analisis yang dilakukan ternyata data awal dan akhir dari satu kelompok eksperimen dalam penelitian memenuhi persyaratan untuk dilakukan pengujian hipotesis. Dalam penelitian ini ada satu hipotesis penelitian, yaitu: terdapat pengaruh yang signifikan antara latihan plyometric terhadap peningkatan kemampuan jumping smash. Data pengukuran pre-test kemampuan jumping smash menggunakan latihan plyometric diperoleh rata-rata 3,35 , sedangkan pada post-test diperoleh 9, 4. Dasar pengambilan terima $\mathrm{H}_{a}$ jika thitung $>$ tabel pada taraf signifikansi 0,05 dan $\mathrm{dk}=\mathrm{n}-1=19$.

\section{Pembahasan}

Dari hipotesis terdapat pengaruh yang signifikan antara metode latihan plyometric terhadap peningkatan kemampuan jumping smashbola voli. Hal ini dapat dilihat dari ratarata peningkatan kemampuan jumping smash dalam 5 kali smash tiap pelaksanaan melalui data tes awal (pre-test) dan data tes akhir (post-test). Peningkatan rata-ratakemampuan jumping smash dalam 5 kali smash tiap pelaksanaan dengan latihan plyometric, tes awalnya 3,35 meningkat menjadi 9,4 (meningkat 6 point). Selanjutnya dari hasil analisis yang menyatakan bahwa terdapat pengaruh yang signifikan antara latihan plyometricterhadap peningkatan kemampuan jumping smash ini dibuktikan dengan hasil analisis yang didapat thitung $=-4,14$ lebih kecil dari tabel $=1,740$. Bahwa latihan plyometric dapat diterapkan dalam mempelajari kemampuan jumping smash bola voli.

Setelah diamati pada waktu penelitian, peneliti melihat latihan plyometric sangat diperlukan untuk meningkatkan kemampuan jumping smash. Dengan melakukan latihan plyometric yang panjang secara terprogram, sistematis, terarah, dan berkesinambungan maka akan meningkatkan kemampuan jumping smash. Tapi bagi atlet yang sering tidak hadir dalam pelaksanaan program latihan, maka peningkatan kemampuan jumping smash akan lebih rendah dibandingkan atlet yang selalu mengikuti program latihan plyometric.

Disamping itu, juga diperlukan konsentrasi terhadap stimulasi yang datang dengan cepat. Semakin banyak atlet mengalami aktivitas gerak tentu unsur-unsur kemampuan motorik semakin terlatih. Kemampuan motorik merupakan kualitas kemampuan seseorang yang dapat mempermudah dalam melakukan keterampilan gerak. Untuk menilai kualitas keterampilan gerakan bisa dilihat melalui ciriciri koordiinasi gerakan yang ditampilkan.

Menurut Schnabel dan Meinel dalam Syafruddin (2011:60) ada sembilan ciri-ciri koordinasi gerakan, yaitu : 1. Struktur gerakan, 2. Irama gerakan, 3. Hubungan gerakan, 4. Luas gerakan, 5. Kelancaran gerakan, 6. Tempo gerakan, 7. Kekuatan gerakan, 8. Ketepatan gerakan, 9. Kekonstanan gerakan.

Dari uraian di atas, dapatdisimpulkan bahwa dalam melakukan latihan plyometric secara berkesinambungan, maka akan meningkatkan kemampuan jumping smash. 
Selain itu, masih ada faktor yang mempengaruhi seperti: sarana dan prasarana, dan motivasi juga sangat menentukan keberhasilan dalam melakukan latihan. Faktor-faktor ini juga tidak bisa diabaikan dalam upaya peningkatan kemampuan jumping smash

\section{PENUTUP \\ Simpulan}

Berdasarkan hasil penelitian yang dilakukan selama satu bulan terakhir dan dilakukan dalam tiga kali dalamseminggu dan pengujian hipotesis dengan mengolah data baik prasyarat maupun mencari perbandingan apakah ada peningkaan ataukah tidak dalam penelitian ini, dengan cara melakukan uji awal atau pre-test didapatkan hasil awal dan setelah dilakukan perlakuan maka diakhir dilakukan post-test atau tes akhir untuk mengetahui adakah peningkatan atau tidak. Maka dapat ditarik kesimpulan yaitu terdapat pengaruh yang signifikan antara latihan plyometric terhadap kemampuan jumping smash. Dengan nilai thitung $>$ tabel $(4,14>1,74)$. Dengan demikian plyometric berpengaruh terhadapjumping smashyaitu sebesar (17,13\%) Dari simpulan maka menjelaskan bahwa ada pengaruh latihan plyometric terhadap kemampuan jumping smash

\section{Saran}

Adapun saran-saran yang dapat dikemukakan sesuai hasil penelitian, pembahasan, dan kesimpulan yang telah diuraikan adalah:

1. Bagi pelatih bola voli agar dapat memberikan materi yang tepat dan penyusunan program latihan khususnya untuk melatih keterampilan dan kemampuan jumping smash yang di dukung oleh materi lainnya guna meningkatkan teknik dasar bola voli sehingga dapat mendukung dalam memperoleh poin

2. Bagi atlet agar dapat mengembangkan kemampuan bermain bola $\mathrm{v} 0 \mathrm{I}$ dalam melakukan kemampuan jumping smash khususnya berdasarkan analisa dalam penelitian ini.

3. Bagi dosen atau guru pendidikan jasmani dan olahraga agar dapat lebih memperhatihan faktor-faktor dan variabel lain yang dapat meningkatkan kemampuan jumping smash dalam permainan bola voli.

4. Bagi peneliti lain yang ingin melakukan penelitian lebih lanjut agar dapat menjadikan penelitian ini sebagai bahan informasi dan dapat meneliti dengan jumlah populasi serta sampel yang lebih banyak dan berbeda.

\section{DAFTAR PUSTAKA}

Arikunto, Suharsimi. (2006). Prosedur Penelitian Suatu Pendekatan Praktik. Jakarta: PT Rineka Cipta.

Johansyah.Lubis. (2013). Panduan Praktis

Penyusunan Program Latihan. Jakarta. PT. Raja Grafindo Persada.

M. Subana. (2005). Dasar dasar Penelitian IImiah..Bandung.Cv.PustakaSetia

Sugiyono (2006). Metode Penelitian Kuantitatif, Kualitatif dan $R \& D$. Bandung.Alfabeta

Sugiyono. (2012). Metode Penelitian Kuantitatif, Kualitatif dan $R \& D$. Bandung. Alfabeta. 